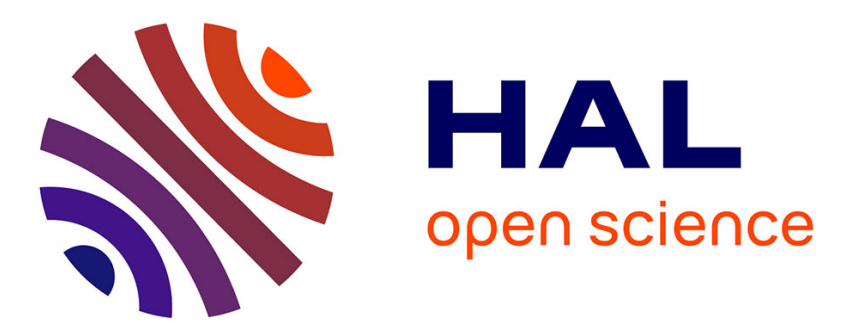

\title{
A Karplus Equation for the Conformational Analysis of Organic Molecular Crystals
}

Pierre Thureau, Isaure Carvin, Fabio Ziarelli, Stéphane S Viel, Giulia Mollica

\section{To cite this version:}

Pierre Thureau, Isaure Carvin, Fabio Ziarelli, Stéphane S Viel, Giulia Mollica. A Karplus Equation for the Conformational Analysis of Organic Molecular Crystals. Angewandte Chemie International Edition, 2019, 58 (45), pp.16047-16051. 10.1002/anie.201906359 . hal-02354508

\section{HAL Id: hal-02354508 https://hal.science/hal-02354508}

Submitted on 16 Sep 2021

HAL is a multi-disciplinary open access archive for the deposit and dissemination of scientific research documents, whether they are published or not. The documents may come from teaching and research institutions in France or abroad, or from public or private research centers.
L'archive ouverte pluridisciplinaire HAL, est destinée au dépôt et à la diffusion de documents scientifiques de niveau recherche, publiés ou non, émanant des établissements d'enseignement et de recherche français ou étrangers, des laboratoires publics ou privés. 
This is the peer reviewed version of the following article: $A$ Karplus equation for the conformational analysis of organic molecular crystals, which has been published in final form at https://onlinelibrary.wiley.com/doi/abs/10.1002/anie.201906359. This article may be used for non-commercial purposes in accordance with Wiley Terms and Conditions for Use of Self-Archived Versions. This article may not be enhanced, enriched or otherwise transformed into a derivative work, without express permission from Wiley or by statutory rights under applicable legislation. Copyright notices must not be removed, obscured or modified. The article must be linked to Wiley's version of record on Wiley Online Library and any embedding, framing or otherwise making available the article or pages thereof by third parties from platforms, services and websites other than Wiley Online Library must be prohibited.

\title{
A Karplus equation for the conformational analysis of organic molecular crystals
}

\author{
Pierre Thureau, ${ }^{[\mathrm{a}]}$ Isaure Carvin, ${ }^{[\mathrm{a}]}$ Fabio Ziarelli, ${ }^{[\mathrm{b}]}$ Stéphane Viel, ${ }^{[\mathrm{a}],[\mathrm{cc}}$ Giulia Mollica ${ }^{*[\mathrm{a}]}$
}

\begin{abstract}
Vicinal scalar couplings $\left({ }^{3} \mathrm{~J}\right)$ are extensively used for conformational analysis of organic compounds in the liquid state through the use of empirical Karplus equations. Contrastingly, there are no examples of such use for structural investigation of solids. With the support of first principles calculations, we demonstrate here that ${ }^{13} \mathrm{C}-{ }^{13} \mathrm{C}{ }^{3} \mathrm{~J}\left({ }^{3} \mathrm{JcC}\right)$ measured on a series of isotopically-enriched solid amino acids and sugars can be related to dihedral angles by a simple Karplus-like relationship, and we provide a parameterized Karplus function for the conformational analysis of organic molecular crystals. Under the experimental conditions discussed, torsional angles can be estimated from the experimental ${ }^{3} \mathrm{Jcc}$ with an accuracy of $10^{\circ}$ using this function. These results open new perspectives towards the use of ${ }^{3} J_{c c}$ as a new analytical tool that could considerably simplify structure determination of functional organic solids.
\end{abstract}

Accessing the atomic-level structure of functional materials is an essential prerequisite to understand the physical origin of their functionality. ${ }^{[1]}$ Interestingly, functional materials composed of small organic molecules are very prone to polymorphism, i.e. they can assume different crystalline forms. ${ }^{[2]}$ Because different polymorphs of the same chemical compound display distinct physicochemical properties, polymorphism might be an opportunity to tune the properties of a given functional material, with great value for industrial applications in pharmacy or energyrelated fields. ${ }^{[3]}$ Recently, crystal structure prediction (CSP) has shown that polymorphism of organic molecular crystals is intimately linked with the conformational flexibility of the molecule. ${ }^{[4]}$ The reverse is also true, i.e. the molecular

[a] Dr. P. Thureau, I. Carvin, Prof. S. Viel, Dr. G. Mollica Aix Marseille Univ, CNRS

ICR UMR 7273

Marseille, France

E-mail: giulia.mollica@univ-amu.fr

[b] Dr. F. Ziarelli

Aix Marseille Univ, CNRS

Centrale Marseille, FSCM

FR1739

Marseille, France

[c] Prof. S. Viel

Institut Universitaire de France

Paris, France

Supporting information for this article is given via a link at the end of the document. conformation of flexible molecules in the solid state is strongly connected to the global crystal structure and cannot be simply inferred from the knowledge of the molecular geometry in the gas state or in solution. CSP methods have progressed in predicting molecular conformations for flexible molecules in the solid state. ${ }^{[5]}$ However, because the dimensionality of the energy landscape increases with increasing the conformational degrees of freedom, obtaining good structural models from CSP to be used for solving the crystal structure of an unknown solid can be computationally very expensive for this kind of compounds.

One approach to help structure determination of solids is to reduce the dimensionality of the landscape explored by CSP by providing constraints obtained experimentally.

Solid-state nuclear magnetic resonance (SSNMR) is a very powerful approach to get atomic-level structural information on materials. Among the accessible NMR measurables, spin-spin $J$ (or scalar) couplings are of exceptional value for conformational analysis. ${ }^{[6]}$ In liquid-state NMR, the experimental dependence of three-bond $J$ coupling constants $\left({ }^{3} J\right)$ on torsional angles ${ }^{[7]}$ through the well-known Karplus equations ${ }^{[8]}$ has been extensively used for conformational analysis of small organic molecules, ${ }^{[9]}$ peptides and proteins. ${ }^{[10]}$ However, examples of the use of $J$ couplings for structural analysis in the solid state are much more sparse in the literature, where they have mostly been reported for inorganic nuclei ${ }^{[11]}$ and on disordered solids. ${ }^{[12]}$ This difficulty is due to the fact that the scalar interaction between two spins can be several orders of magnitude smaller than the other active anisotropic spin interactions (e.g. quadrupolar, CSA, dipolar interactions), making it hardly detectable. This effect is exacerbated in the case of longrange scalar couplings, such as ${ }^{3} \mathrm{~J}$, which are characterized by correspondingly smaller coupling constants. Additionally, typical ${ }^{3} \mathrm{~J}$ couplings in organic solids generate splitting patterns of a few $\mathrm{Hz}$ that are generally obscured in the SSNMR spectra by inhomogeneous line broadening, preventing the direct measurement of the corresponding coupling constant. Notwithstanding these experimental difficulties, several methodologies have been proposed to indirectly measure $J$ couplings in solids, which are mostly based on the use of rotorsynchronized spin-echo experiments under magic-angle spinning $(\mathrm{MAS})^{[13]}$ on isotopically enriched samples. In several studies, Emsley, Brown and coworkers showed that spin echo experiments are very efficient to detect the presence of hydrogenbond mediated $J$ couplings in organic solids $\left({ }^{2 h} J\right) \cdot{ }^{[14]}$ For instance, 
${ }^{2 h} J_{N N}$ constants ranging between ca. 4 and $10 \mathrm{~Hz}$ could be measured in self-assembled guanosines, ${ }^{[15]}$ showing very good agreement with the values computed by DFT on the corresponding periodic structures. ${ }^{[16]}$ Recently, our group demonstrated that homonuclear ${ }^{13} \mathrm{C}-{ }^{13} \mathrm{C}{ }^{3} \mathrm{~J}$ couplings as small as $1 \mathrm{~Hz}$ can be measured in ${ }^{13} \mathrm{C}$-enriched organic powders with the help of selective rotor-synchronized spin echo experiments. ${ }^{[17]}$ Although these applications were useful to confirm or discover the presence of specific structural motifs, such as hydrogen bonds, no systematic attempt has ever been made, to the best of our knowledge, at obtaining quantitative structural information, such as torsional angles, from the value of $J$ couplings in the solid state. With the support of first principles calculations, we show in this study that a simple Karplus relationship relates ${ }^{13} \mathrm{C}-{ }^{13} \mathrm{C}{ }^{3} \mathrm{~J}$ couplings - measured for a series of small ${ }^{13} \mathrm{C}$-enriched organic solids only composed of $\mathrm{C}, \mathrm{N}, \mathrm{O}$ and $\mathrm{H}$ atoms - to the dihedral

\section{a)}
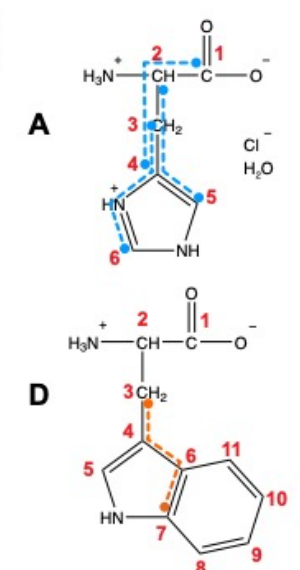
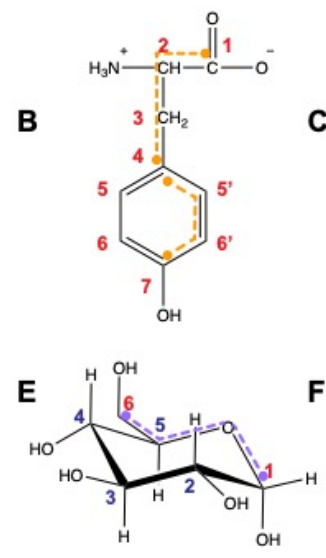

C
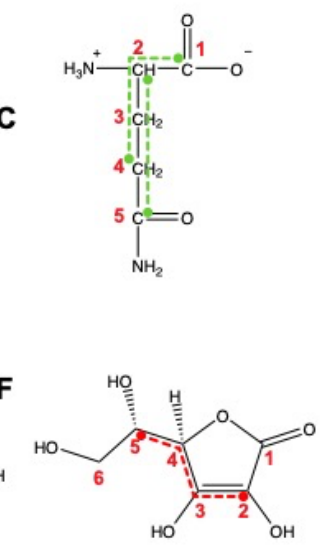

b)

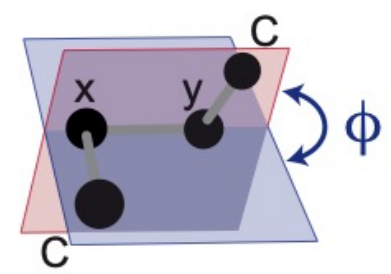

Figure 1. a) Chemical structures of the molecular crystals investigated: A, L-histidine $\mathrm{HCl} \cdot \mathrm{H}_{2} \mathrm{O}$; $\mathbf{B}, \mathrm{L}$-tyrosine; C, L-glutamine; $\mathbf{D}$, L-tryptophan; E, $\mathbf{a}$-D-glucose; $\mathbf{F}$, $\mathrm{L}$-ascorbic acid. Red and blue numbers refer to ${ }^{13} \mathrm{C}$-enriched and natural isotopic abundance carbon atoms, respectively, used for the experimental measurements of ${ }^{3} \mathrm{~J}$ couplings. Dotted lines indicate the pathway of ${ }^{3} \mathrm{~J}$ coupling through the three chemical bonds linking the two coupled carbon atoms, indicated with a plain circle. b) Torsional angle $\phi$ for the molecular fragment $\mathrm{CxyC}$.

angle of the corresponding molecular fragment. Using the dihedral angles from the known crystal structures (see ESI), we parameterize a ${ }^{13} \mathrm{C}-{ }^{13} \mathrm{C}$ Karplus function for organic molecular crystals and we prove that it can successfully provide the dihedral angle in a polycrystalline solid compound of known structure, Lthreonine, with an accuracy of $10^{\circ}$.

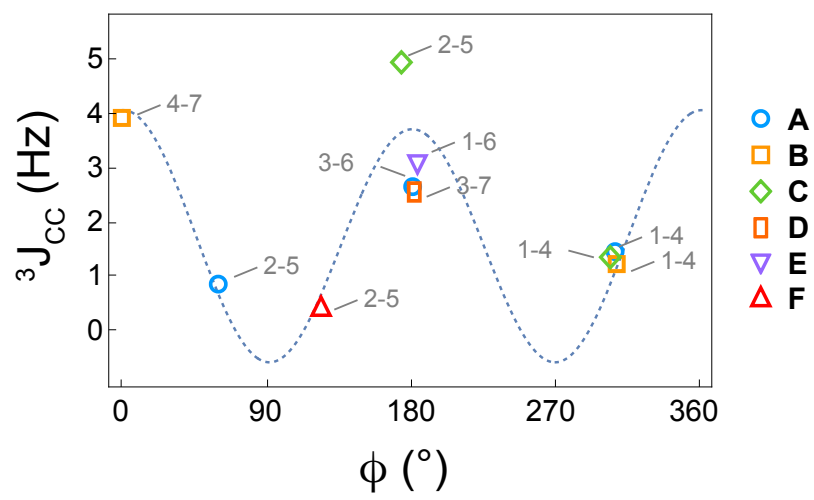

Figure 2. Calculated ${ }^{3} J_{C C}$ for the set of organic molecular crystals investigated. ${ }^{3} J_{\mathrm{CC}}$ values are plotted against the torsional angle of the molecular fragments in the corresponding crystal structure. The Karplus function reported by Berger for similar organic compounds in solution, ${ }^{[9]}$ corresponding to Eq. 1, is shown as a dashed line. Labeling refers to Figure 1. Error bars for $\phi$ are approximately on the scale of the marker sizes. Color code is the same as Figure 1.

The existence of a Karplus dependence for three-bond carboncarbon $J$ coupling constants $\left({ }^{3} J_{C C}\right)$ in the solid state was tested on a set of six organic molecules (of ca. 30 atoms). It is well known that, even in the liquid state, establishing dihedral angle dependence of ${ }^{3} J_{C c}$ can be complicated by substituent effects and through-space interactions. ${ }^{[7,18]}$ Nonetheless, in this investigation, no particular restriction was applied to the choice of the compounds to be analyzed. On the contrary, the set of selected samples, although only composed of $\mathrm{C}, \mathrm{O}, \mathrm{N}$ and $\mathrm{H}$ atoms, was purposely chosen to include ${ }^{3} J_{c c}$ acting through various types of chemical bonds and heteroatoms in the solid state. Figure 1 shows the chemical structures of these compounds together with the molecular fragments corresponding to the ${ }^{3} \mathrm{Jcc}$ taken into account in the analysis, indicated by dotted lines. The crystal structure of all these substances had been previously determined and deposited in the Cambridge Structural Database (CSD) with the entry references reported in Table 1 . Table 1 also shows the dihedral angles $(\phi)$ for the $C x y C$ molecular fragments (Figure 1) obtained after geometry-optimization of the corresponding CSD structures. The standard deviations associated with the values of dihedral angles were estimated from the CSD crystal structures before geometry optimization and are also reported in Table 1.

To assess the existence of a Karplus-like relationship between ${ }^{3} J_{\mathrm{CC}}$ and the molecular conformation in the solid state, first principles calculations of $J_{c c}$ were performed using the optimized crystal structures of compounds $\mathbf{A}-\mathbf{F}$, as well as four additional crystal structures (namely anhydrous ampicillin, ibuprofen, flufenamic acid and cocaine), as inputs. A total of 22 computed ${ }^{3} J_{c c}$ were analyzed (see ESI). For clarity, Figure 2 only shows the results of $J$ calculations for molecules A-F, which are plotted as a function of the dihedral angle in the corresponding geometryoptimized crystal structure and compared to the following Karplus-like function:

$$
{ }^{3} J_{C C}(\varphi)=1.67+0.18 \operatorname{Cos}(\varphi)+2.24 \operatorname{Cos}(2 \varphi)
$$


which was obtained by Berger from multiple regression of ${ }^{3} \mathrm{~J}_{\mathrm{CC}}$ measured on a set of 22 organic molecules in the liquid state. ${ }^{[9]}$ We note that, because Karplus-like curves are symmetric with respect to $\phi=180^{\circ}$, we could have only shown the portion $0-180^{\circ}$ of the curve (i.e. without specifying the sign of the torsional angle). However, the whole range $0-360^{\circ}$ was shown here because the true angles were known from the crystal structures. Importantly, as explained in the ESI, the calculated value of ${ }^{3} J_{47}$ for tyrosine

Table 1. Calculated and experimental ${ }^{3} \mathrm{Jcc}_{\mathrm{cc}}$ corresponding to the $C x y C$ three-bond molecular fragment for the investigated molecular crystals, together with their CSD entry reference. $\phi$ is the corresponding torsional angle in the geometry-optimized structure. Experimental standard deviations for dihedral angles are also shown. The number of crystallographically distinct molecules composing the crystal asymmetric unit, $Z$ ', is also indicated.

\begin{tabular}{|c|c|c|c|c|c|c|c|}
\hline Sample & CSD entry & $Z^{\prime}$ & ${ }^{3} J_{C C}$ & $\boldsymbol{C x y}^{[\mathrm{a}]}$ & $\phi\left[^{\circ}\right]$ & Calc $[\mathrm{Hz}]^{[\mathrm{b}]}$ & $\operatorname{Exp}[\mathrm{Hz}]^{[\mathrm{c}]}$ \\
\hline \multirow[t]{3}{*}{ A } & HISTCM12 & 1 & ${ }^{3} J_{14}$ & 1234 & $-53.5 \pm 0.2$ & 1.5 & $1.9 \pm 0.4$ \\
\hline & & & ${ }^{3} J_{25}$ & 2345 & $59.7 \pm 0.2$ & 0.9 & $1.6 \pm 0.3$ \\
\hline & & & ${ }^{3} J_{36}$ & $34 N 6$ & $-179.1 \pm 0.1$ & 2.7 & $3.8 \pm 0.2$ \\
\hline \multirow[t]{2}{*}{ B } & LTYROS11 & 1 & ${ }^{3} J_{14}$ & 1234 & $-51.9 \pm 0.2$ & 1.2 & $1.1 \pm 0.4$ \\
\hline & & & ${ }^{3} J_{47}$ & 4567 [d] & $0.9 \pm 0.2$ & 7.8 & $9.2 \pm 0.4$ \\
\hline \multirow[t]{2}{*}{ C } & GLUTAM02 & 1 & ${ }^{3} J_{14}$ & 1234 & $-56.4 \pm 0.2$ & 1.4 & $1.6 \pm 0.4$ \\
\hline & & & ${ }^{3} J_{25}$ & 2345 & $174.1 \pm 0.2$ & 5.0 & $5.2 \pm 0.2$ \\
\hline$D^{[e]}$ & VIXQOK01 & 16 & ${ }^{3} J_{37}$ & 3467 & $-178.3 \pm 0.5$ & 2.6 & $2.8 \pm 0.2$ \\
\hline E & GLUCSA26 & 1 & ${ }^{3} J_{16}$ & 1056 & $-176.5 \pm 0.2$ & 3.1 & $3.2 \pm 0.2$ \\
\hline $\mathbf{F}[\mathrm{e}]$ & LASCAC14 & 2 & ${ }^{3} J_{25}$ & 2345 & $123.8 \pm 0.1$ & 0.5 & $1.1 \pm 0.2$ \\
\hline
\end{tabular}

[a] Numbering refers to carbon atoms, only, heteroatoms are indicated with their corresponding chemical symbol; [b] calculated ${ }^{3} J_{c c}$ values obtained after geometry optimizing the CSD structures with fixed unit-cell parameters; [c] experimental ${ }^{3} J_{C c}$ obtained as the average of the values measured observing each of the two carbon signals involved in the coupling; [d] ${ }^{3} \mathrm{Jcc}_{\mathrm{c}}$ receiving additive contributions from multiple three-bond paths: two equivalent pathways are available for the ${ }^{3} J_{47}$ coupling in B, 4567 and $45^{\prime} 6^{\prime} 7$ (see ESI); [e] for samples with Z’>1, only the ${ }^{3} J_{c c}$ for which the corresponding dihedral angle varies by less than $5^{\circ}$ among the $Z^{\prime}$ non-equivalent molecules composing the asymmetric unit are retained for the analysis.

Figure 2 shows that Eq. 1 is in good agreement with the computed ${ }^{3} J_{c c}$ for the expected dihedral angles. As shown in Table S2 and Fig. S3 (ESI), these results are confirmed when analyzing all the 22 calculated couplings. Interestingly, for $\phi=180^{\circ}$ (i.e. " $E "$ fragments) ${ }^{3} J_{\mathrm{cc}}$ span a large range, between 2.8 and $5.2 \mathrm{~Hz}$. However, as explicitly mentioned by Krivdin, ${ }^{77 b]}$ significant spread in ${ }^{3} \mathrm{~J}_{\mathrm{CC}}$ in correspondence of the Karplus curve maxima (i.e. for $\phi=0^{\circ}$ and $\phi=180^{\circ}$ ) was already observed by Marshall after analyzing a large number of saturated alicyclic alcohols, aldehydes and carboxylic acids in solution. ${ }^{[7 b, 20]}$ Moreover, this phenomenon was also observed in proteins $^{[21]}$ and carbohydrates. ${ }^{[22]}$ Although a general explanation has not been reported, it has been observed that the presence of substituent groups with different electronegativity has a particularly strong impact on the $J$ coupling values of planar fragments. ${ }^{[7 b]}$ We also note that, because the coefficient of the term in $\operatorname{Cos}(\phi)$ is small in

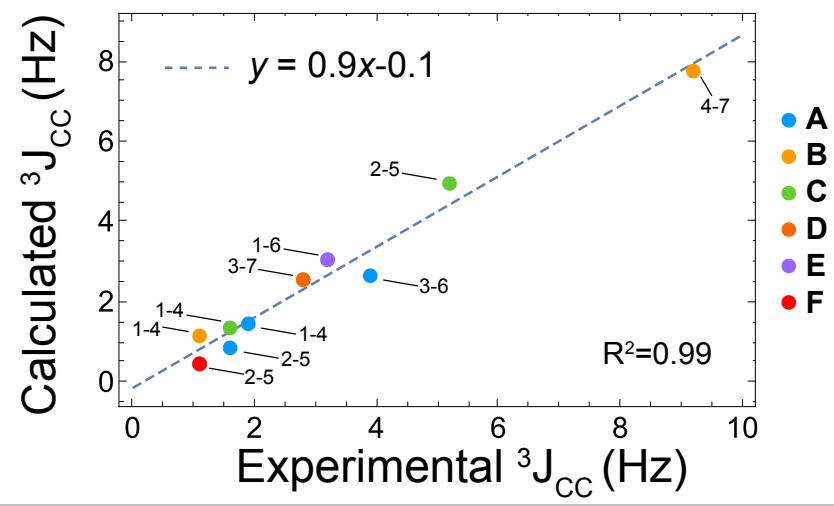

Eq. 1, this function defines a Karplus curve that is almost symmetric with respect to $\phi=90^{\circ}$, making it not very efficient to distinguish $Z$ and $E$ conformations.

Figure 3. Correlation between experimental and calculated ${ }^{3} \mathrm{Jcc}_{\mathrm{cc}}$ for the molecular crystals investigated. $R^{2}$ coefficient is 0.99 . The dashed line indicates linear regression of the data. Color code and labeling refer to Figure 1.

The results of this theoretical investigation on more than 20 computed ${ }^{3} \mathrm{JCc}$ strongly suggested that a Karplus-like behavior relates ${ }^{3} J_{c c}$ to dihedral angles in organic molecular crystals. We were interested to see whether these systems could be used to parameterize a Karplus function that could be subsequently used to extrapolate dihedral angles from the experimental measurement of ${ }^{3} \mathrm{Jcc}$. To this aim, ${ }^{3} \mathrm{Jcc}$ were measured in the solid state with the help of selective spin-echo experiments for the same molecular fragments of the compounds A-F (see ESI). As described in Ref. ${ }^{[17]}$, these experiments allow ${ }^{3} \mathrm{JCC}_{\mathrm{CC}}$ as small as a few $\mathrm{Hz}$ to be measured accurately on ${ }^{13} \mathrm{C}$-labeled samples. The measured ${ }^{3} \mathrm{Jcc}_{\mathrm{cc}}$ are reported in Table 1.

As shown in Figure 3 , the calculated and experimental ${ }^{3} J_{c c}$ show a very good agreement, the $R^{2}$ coefficient being 0.99 . Interestingly, the ${ }^{3} J_{47}$ and ${ }^{3} J_{25}$ coupling constants measured for $\mathbf{B}$ and $\mathbf{C}$, respectively, reflect well the large values previously computed on the full crystal lattices. Linear regression of these data using the function $y=a x+b$ provides $a=0.9$ and $b=-0.1$, suggesting that, in the 1-8 $\mathrm{Hz}$ range, calculations tend to slightly underestimate the experimental coupling constants (or, viceversa, experiments to overestimate calculations). When the data are fitted by fixing $a=1$, the best fit is provided by $y=x-0.5$, indicating an average shift of - 
$0.5 \mathrm{~Hz}$ between experimental and calculated values (see ESI). We note that systematic deviations between computed and experimental $J$ values have already been reported in the liquid state for small molecules and proteins. ${ }^{[9,21]}$

Figure 4 shows the experimental ${ }^{3} J_{c c}$ values plotted versus the dihedral angles for the corresponding molecular fragments. As for the computed value, the experimentally measured value of ${ }^{3} J_{47}$ for tyrosine $(9.2 \mathrm{~Hz})$, too, was halved to take into account the presence of two identical 3-bond coupling pathways (see discussion in the ESI). To obtain a Karplus function to be used for the conformational analysis of solid organic compounds, the 10 experimental $\left[{ }^{3} J_{c c}, \phi\right]$ pairs shown in Figure 4 were fitted to the generic Karplus function:

${ }^{3} J_{C C}(\varphi)=A+B \operatorname{Cos}(\varphi)+C \operatorname{Cos}(2 \varphi)$

providing the following parameterized Karplus equation:

$$
{ }^{3} J_{C C}(\varphi)=2.13+0.32 \operatorname{Cos}(\varphi)+2.07 \operatorname{Cos}(2 \varphi)
$$

We note that Eq. 3 was obtained using known torsional angles, which could hence be expressed in the range $0-360^{\circ}$, i.e. taking into account the sense of the torsion. However, because Karplus functions are symmetric with respect to $\phi=180^{\circ}$, Eq. 3 is not modified if all the torsional angles are defined between 0 and $180^{\circ}$ (i.e. without taking into account the sign of the rotation).

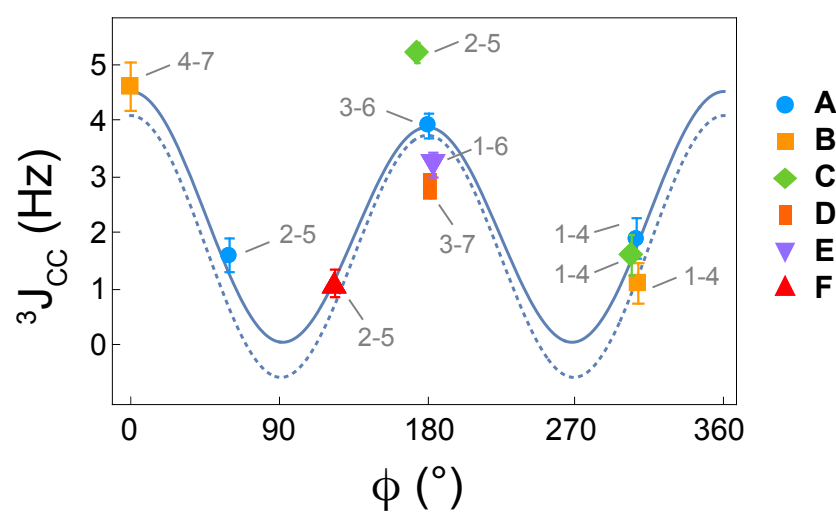

Figure 4. Experimental ${ }^{3} J_{\mathrm{CC}}$ for the set of organic molecular crystals investigated. ${ }^{3} J_{\mathrm{CC}}$ values are plotted against the torsional angle of the molecular fragments in the corresponding crystal structure. The Karplus function reported by Berger for similar organic compounds in solution, ${ }^{[9]}$ corresponding to Eq. 1, is shown as a dashed line, while the Karplus-like function providing the best fit to the experimental values corresponds to Eq. 3. Labeling refers to Figure 1. Error bars for $\phi$ are approximately on the scale of the marker sizes. Color code is the same as Figure 1.

It is interesting to note that the value of $A$ in Eq. 3 is shifted by $+0.46 \mathrm{~Hz}$ with respect to the same parameter for the Berger function, reflecting the previously discussed average shift of 0.5 $\mathrm{Hz}$ between the values of calculated and experimental ${ }^{3} \mathrm{Jcc}$. Moreover, we observe that the value of $B$ is significantly larger in Eq. 3 than in Eq. 1, suggesting that Eq. 3 should be able to provide better discrimination between $E$ and $Z$ fragments.

The root mean square deviation (RMSD) between the experimental dihedral angles and the angles determined using Eq 3 for the measured ${ }^{3} \mathrm{Jcc}$ values was also estimated (see ESI). Bax and coworkers repeatedly used RMSD to evaluate the quality of parameterized Karplus functions for structural investigation of proteins in the liquid state. ${ }^{[21,23]}$ Our data provided an RMSD of $6^{\circ}$. Remarkably, this value is of the same order of magnitude as the accuracy obtained with ${ }^{3} \mathrm{~J}$, dipolar, or chemical shift-based methods for torsional angle determination in proteins or peptides (see for instance Refs. ${ }^{[24]}$ ). As the sole example of Karplus-like function parameterized in the case of organic solids, Eq. 3 might hence be useful to estimate the dihedral angles in small organic solids from the simple measurement of the ${ }^{3} J_{c c}$ for the corresponding molecular fragment, without the need of first principle calculations. As discussed in the ESI, the uncertainty in torsional angle determination for the range of ${ }^{3} J_{\mathrm{Cc}}$ and $\sigma_{J}$ (i.e. the uncertainty associated with the experimental measurement of ${ }^{3} J_{\mathrm{CC}}$ ) shown in Table 1 (i.e. for ${ }^{3} J_{\mathrm{CC}}>1 \mathrm{~Hz}$ and $0.2<\sigma_{J}<0.4 \mathrm{~Hz}$ ), can also be estimated from $\sigma_{J}$ to be less than $10^{\circ}$. This value is of the same order of magnitude of the RMSD calculated for Eq. 3. The possibility of deducing $\phi$ from the measurement of ${ }^{3} \mathrm{Jcc}$ using Eq. 3 was tested on the solid amino acid L-threonine. Figure S9 (ESI) shows that, for an experimentally measured ${ }^{3} J_{13}$ value of $1.85 \mathrm{~Hz}$, Eq. 3 predicts two possible dihedral angles for the 1-23-4 fragment of L-threonine in the range between $0^{\circ}$ and $180^{\circ}$ (i.e., only considering the absolute value of the torsional angle). Interestingly, one of these two torsional angles, indicated by a red arrow in Figure $\mathrm{S} 9$ and corresponding to $52^{\circ}$, differs by less than $10^{\circ}$ from the true dihedral angle $\left(61^{\circ}\right.$, extracted from the CSD crystal structure of L-threonine after geometry optimization). This difference lies within the previously estimated uncertainty in angle determination, suggesting that Eq. 3 can be used to constrain the conformational search in organic molecular crystals in the solid state with the expected level of accuracy. Incidentally, we also note that the torsional angle of the 1-2-3-4 fragment of an isolated L-threonine molecule after geometry optimization in a vacuum supercell would be $71^{\circ}$. This observation confirms that crystal packing can induce substantial conformational rearrangement with respect to gas or liquid state and reinforces the importance of determining torsional angles in the solid state for reliable structural analysis.

In conclusion, we verified the opportunity of exploiting three-bond ${ }^{13} \mathrm{C}-{ }^{13} \mathrm{C} J$ couplings for the conformational analysis of solid organic compounds only composed of $\mathrm{C}, \mathrm{O}, \mathrm{N}$ and $\mathrm{H}$ atoms.

With the support of DFT calculations on periodic structures, we observed that a Karplus-like function relates the values of the total calculated ${ }^{3} J_{c c}$ couplings to the dihedral angle $\phi$ of the corresponding molecular fragment. Surprisingly, calculations revealed that the predicted $\left[{ }^{3} J_{\mathrm{CC}}, \phi\right]$ values display the same general Karplus behavior independently of the differences in substituent groups or supramolecular interactions present among the different molecular solids considered, the largest deviations being observed for planar fragments. Using ${ }^{13} \mathrm{C}$-enriched powder samples, the $10{ }^{3} J_{\mathrm{CC}}$ of samples A-F were also measured experimentally with the help of rotor-synchronized spin echo experiments, confirming the type of relationship observed from calculations and showing that the calculated and experimental ${ }^{3} \mathrm{JCC}_{\mathrm{CC}}$ values are shifted by an average of $0.5 \mathrm{~Hz}$. Best-fitting the experimental data with a Karplus-like function provided the first Karplus relationship ever reported for solid samples to the best of our knowledge.

We demonstrated that this function allows the dihedral angle for the 1-2-3-4 molecular fragment of the solid amino acid L-threonine to be estimated within the expected angle accuracy of $10^{\circ}$.

We expect that these findings will allow scalar couplings - today severely underexploited for the structural investigation of organic powders - to be included into current NMR crystallography 
approaches, providing structural information complementary to that obtained using other NMR measurables, such as chemical shifts and dipolar couplings ${ }^{[25]}$, and opening new avenues towards non-invasive structure determination of powders. Moreover, we anticipate that combining this information with crystal structure prediction will significantly improve crystal structure search, making structure solution for organic solids more rapid and reliable.

\section{Acknowledgements}

The authors thank Prof. J. R. Yates for helpful discussions. This project has received funding from the European Research Council (ERC) under the European Union's Horizon 2020 research and innovation programme (grant agreement No 758498). This work was granted access to the HPC resources of Aix-Marseille Universite financed by the project Equip@Meso (ANR-10-EQPX-29-01) of the program "Investissements d'Avenir" supervised by the Agence Nationale de la Recherche.

Keywords: crystal $\cdot$ dihedral angle $\cdot$ geometry $\cdot$ GIPAW $\cdot \mathrm{J}$ coupling $\bullet$ NMR crystallography $\cdot$ NMR spectroscopy $\bullet$ scalar coupling $\bullet$ solid-state structures $\bullet$ vicinal coupling $\bullet$ polymorphism - powder • torsional angle.

\section{References}

[1] aJ. Cornil, D. Beljonne, J. P. Calbert, J. L. Brédas, Adv. Mat. 2001, 13, 1053-1067; bG. Giri, E. Verploegen, S. C. B. Mannsfeld, S. AtahanEvrenk, D. H. Kim, S. Y. Lee, H. A. Becerril, A. Aspuru-Guzik, M. F. Toney, Z. Bao, Nature 2011, 480, 504-508; cK. Vasseur, B. P. Rand, D. Cheyns, K. Temst, L. Froyen, P. Heremans, J. Phys. Chem. Lett. 2012, 3, 2395-2400.

[2] aJ. Bernstein, Cryst. Growth Des. 2011, 11, 632-650; bA. J. CruzCabeza, S. M. Reutzel-Edens, J. Bernstein, Chem. Soc. Rev. 2015, 44 8619-8635.

[3] aJ. Bauer, S. Spanton, R. Henry, J. Quick, W. Dziki, W. Porter, J. Morris, Pharm. Res. 2001, 18, 859-866; bO. D. Jurchescu, D. A. Mourey, S Subramanian, S. R. Parkin, B. M. Vogel, J. E. Anthony, T. N. Jackson, D. J. Gundlach, Phys. Rev. B 2009, 80, 085201.

[4] aA. Nangia, Acc. Chem. Res. 2008, 41, 595-604; bH. P. G. Thompson, G. M. Day, Chem. Sci. 2014, 5, 3173-3182.

[5] A. M. Reilly, R. I. Cooper, C. S. Adjiman, S. Bhattacharya, A. D. Boese, J. G. Brandenburg, P. J. Bygrave, R. Bylsma, J. E. Campbell, R. Car, D. H. Case, R. Chadha, J. C. Cole, K. Cosburn, H. M. Cuppen, F. Curtis, G. M. Day, R. A. DiStasio Jr, A. Dzyabchenko, B. P. van Eijck, D. M. Elking, J. A. van den Ende, J. C. Facelli, M. B. Ferraro, L. Fusti-Molnar, C.-A. Gatsiou, T. S. Gee, R. de Gelder, L. M. Ghiringhelli, H. Goto, S. Grimme, R. Guo, D. W. M. Hofmann, J. Hoja, R. K. Hylton, L. luzzolino, W. Jankiewicz, D. T. de Jong, J. Kendrick, N. J. J. de Klerk, H.-Y. Ko, L. N Kuleshova, X. Li, S. Lohani, F. J. J. Leusen, A. M. Lund, J. Lv, Y. Ma, N. Marom, A. E. Masunov, P. McCabe, D. P. McMahon, H. Meekes, M. P. Metz, A. J. Misquitta, S. Mohamed, B. Monserrat, R. J. Needs, M. A. Neumann, J. Nyman, S. Obata, H. Oberhofer, A. R. Oganov, A. M. Orendt, G. I. Pagola, C. C. Pantelides, C. J. Pickard, R. Podeszwa, L. S. Price, S. L. Price, A. Pulido, M. G. Read, K. Reuter, E. Schneider, C. Schober, G. P. Shields, P. Singh, I. J. Sugden, K. Szalewicz, C. R. Taylor, A. Tkatchenko, M. E. Tuckerman, F. Vacarro, M. Vasileiadis, A. Vazquez-Mayagoitia, L. Vogt, Y. Wang, R. E. Watson, G. A. de Wijs, J. Yang, Q. Zhu, C. R. Groom, Acta Crystallogr. B 2016, 72, 439-459.

[6] aJ. Vaara, J. Jokisaari, R. E. Wasylishen, D. L. Bryce, Progr. Nucl. Magn. Reson. Sp. 2002, 41, 233 - 304; bA. Lesage, in eMagRes (Eds.: R. K. Harris, R. E. Wasylishen), Wiley-Blackwell, 2008; cR. H. Contreras, J. E.
Peralta, C. G. Giribet, M. C. R. de azúa, J. C. Facelli, Vol. 41, Academic Press, 2000, pp. 55 - 184.

[7] aJ. L. Marshall, D. E. Miiller, S. A. Conn, R. Seiwell, A. M. Ihrig, Acc. Chem. Res. 1974, 7, 333-339; bL. B. Krivdin, E. W. Della, Prog. Nucl. Magn. Res. Sp. 1991, 23, $301-610$.

[8] M. Karplus, J. Am. Chem. Soc. 1963, 85, 2870-2871.

[9] S. Berger, Org. Magn. Reson. 1980, 14, 65-68.

[10] J. H. Lee, F. Li, A. Grishaev, A. Bax, J. Am. Chem. Soc. 2015, 137, 1432-1435 .

[11] aP. Sanz Camacho, K. S. Athukorala Arachchige, A. M. Z. Slawin, T. F. G. Green, J. R. Yates, D. M. Dawson, J. D. Woollins, S. E. Ashbrook, J. Am. Chem. Soc. 2015, 137, 6172--6175; bC. Martineau, F. Fayon, C. Legein, J.-Y. Buzaré, G. Silly, D. Massiot, Chem. Commun. 2007, 2720-2722; cD. Massiot, F. Fayon, M. Deschamps, S. Cadars, P. Florian, V. Montouillout, N. Pellerin, J. Hiet, A. Rakhmatullin, C. Bessada, Comptes Rendus Chimie 2010, 13, 117 - 129; dF. Fayon, D. Massiot, M. H. Levitt, J. J. Titman, D. H. Gregory, L. Duma, L. Emsley, S. P. Brown, J. Chem. Phys. 2005, 122, 194313; eS. E. Ashbrook, D. McKay, Chem. Commun. 2016, 52, 7186-7204; fY. T. A. Wong, J. Landmann, M. Finze, D. L. Bryce, J. Am. Chem. Soc. 2017, 139, 8200-8211; gF. A. Perras, W. C. Ewing, T. Dellermann, J. Böhnke, S. Ullrich, T. Schäfer, H. Braunschweig, D. L. Bryce, Chem. Sci. 2015, 6, 3378-3382.

[12] aS. Cadars, A. Lesage, M. Trierweiler, L. Heux, L. Emsley, Phys. Chem. Chem. Phys. 2007, 9, 92-103; bJ. M. Griffin, J. R. Yates, A. J. Berry, S. Wimperis, S. E. Ashbrook, J. Am. Chem. Soc. 2010, 132, 15651--15660; cS. Cadars, D. H. Brouwer, B. F. Chmelka, Phys. Chem. Chem. Phys. 2009, 11, 1825-1837; dD. J. Srivastava, J. H. Baltisberger, P. Florian, F. Fayon, R. A. Shakhovoy, M. e. Deschamps, N. Sadiki, P. J. Grandinetti, Phys. Rev. B 2018, 98, 134202.

[13] L. Duma, W. C. Lai, M. Carravetta, L. Emsley, S. P. Brown, M. H. Levitt, ChemPhysChem 2004, 5, 815-833.

[14] aS. P. Brown, M. Perez-Torralba, D. Sanz, R. M. Claramunt, L. Emsley, Chem. Commun. 2002, 1852-1853; bS. P. Brown, L. Emsley, J. Magn. Reson. 2004, 171, 43-47; cl. Hung, A.-C. Uldry, J. Becker-Baldus, A. L. Webber, A. Wong, M. E. Smith, S. A. Joyce, J. R. Yates, C. J. Pickard, R. Dupree, S. P. Brown, J. Am. Chem. Soc. 2009, 131, 1820-1834.

[15] S. A. Joyce, J. R. Yates, C. J. Pickard, S. P. Brown, J. Am. Chem. Soc. 2008, 130, 12663-12670.

[16] aJ. R. Yates, Magn. Reson. Chem. 2010, 48, S23-S31; bT. F. G. Green, J. R. Yates, J. Chem. Phys. 2014, 140, 234106.

[17] P. Thureau, G. Mollica, F. Ziarelli, S. Viel, J. Magn. Reson. 2013, 231, 90-94.

[18] J. L. Marshall, L. G. Faehl, R. Kattner, P. E. Hansen, Org. Magn. Reson. 1979, 12, 169-173.

[19] J. L. Marshall, L. G. Faehl, R. Kattner, Org. Magn. Reson. 1979, 12, 163168.

[20] J. L. Marshall, Carbon-carbon and carbon-proton NMR couplings: applications to organic stereochemistry and conformational analysis, Verlag Chemie International, Deerfield Beach, Florida, 1983.

[21] J.-S. Hu, A. Bax, J. Am. Chem. Soc. 1997, 119, 6360-6368.

[22] B. Bose, S. Zhao, R. Stenutz, F. Cloran, P. B. Bondo, G. Bondo, B. Hertz, I. Carmichael, A. S. Serianni, J. Am. Chem. Soc. 1998, 120, 1115811173.

[23] A. C. Wang, A. Bax, J. Am. Chem. Soc. 1996, 118, 2483-2494.

[24] aM. Hong, J. D. Gross, R. G. Griffin, J. Phys. Chem B 1997, 101, 58695874; bX. Feng, Y. K. Lee, D. Sandstrom, M. Edén, H. Maisel, A. Sebald, M. H. Levitt, Chem. Phys. Lett. 1996, 257, 314-320; cR. Suardíaz, R. Crespo-Otero, C. Pérez, J. S. Fabián, J. M. G. d. I. Vega, J. Chem. Phys. 2011, 134, 061101; dY. Shen, F. Delaglio, G. Cornilescu, A. Bax, J. Biomol. NMR 2009, 44, 213-223; eY. Shen, A. Bax, J. Biomol. NMR 2013, 56, 227-241.

[25] aA. Hofstetter, M. Balodis, F. M. Paruzzo, C. M. Widdifield, G. Stevanato, A. C. Pinon, P. J. Bygrave, G. M. Day, L. Emsley, J. Am. Chem. Soc. 2019, https://doi.org/10.1021/jacs.9b03908; bG. Mollica, M. Dekhil, F. Ziarelli, P. Thureau, S. Viel, Angew. Chem. Int. Ed. 2015, 54, 6028-6031. 
Entry for the Table of Contents (Please choose one layout)

\section{COMMUNICATION}

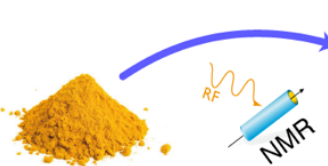

POWDER

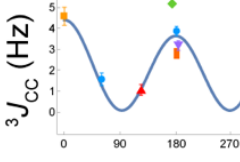

Karplus
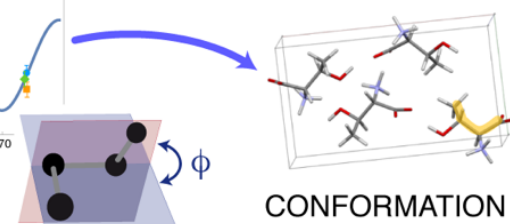

CONFORMATION
P. Thureau, I. Carvin, F. Ziarelli, S. Viel, G. Mollica*

\section{Page No. - Page No.}

Unlocking conformation of organic solids via solid-state NMR

Three-bond $J$ couplings accessed via solid-state NMR on organic solids are related to torsional angles via a simple Karplus relationship. This function constitutes a unique tool to probe the conformation of organic materials that is expected to significantly improve determination of crystal structures for powders. 


\section{References}

[1] aJ. Cornil, D. Beljonne, J. P. Calbert, J. L. Brédas, Adv. Mat. 2001, 13, 1053-1067; bG. Giri, E. Verploegen, S. C. B. Mannsfeld, S. Atahan-Evrenk, D. H. Kim, S. Y. Lee, H. A. Becerril, A. Aspuru-Guzik, M. F. Toney, Z. Bao, Nature 2011, 480, 504-508; cK. Vasseur, B. P. Rand, D. Cheyns, K. Temst, L. Froyen, P. Heremans, J. Phys. Chem. Lett. 2012, 3, 2395-2400.

[2] aJ. Bernstein, Cryst. Growth Des. 2011, 11, 632-650; bA. J. Cruz-Cabeza, S. M. Reutzel-Edens, J. Bernstein, Chem. Soc. Rev. 2015, 44, 8619-8635.

[3] aJ. Bauer, S. Spanton, R. Henry, J. Quick, W. Dziki, W. Porter, J. Morris, Pharm. Res. 2001, 18, 859-866; bO. D. Jurchescu, D. A. Mourey, S. Subramanian, S. R. Parkin, B. M. Vogel, J. E. Anthony, T. N. Jackson, D. J. Gundlach, Phys. Rev. B 2009, 80, 085201.

[4] aA. Nangia, Acc. Chem. Res. 2008, 41, 595-604; bH. P. G. Thompson, G. M. Day, Chem. Sci. 2014, 5, 3173-3182.

[5] A. M. Reilly, R. I. Cooper, C. S. Adjiman, S. Bhattacharya, A. D. Boese, J. G. Brandenburg, P. J. Bygrave, R. Bylsma, J. E. Campbell, R. Car, D. H. Case, R. Chadha, J. C. Cole, K. Cosburn, H. M. Cuppen, F. Curtis, G. M. Day, R. A. DiStasio Jr, A. Dzyabchenko, B. P. van Eijck, D. M. Elking, J. A. van den Ende, J. C. Facelli, M. B. Ferraro, L. Fusti-Molnar, C.-A. Gatsiou, T. S. Gee, R. de Gelder, L. M. Ghiringhelli, H. Goto, S. Grimme, R. Guo, D. W. M. Hofmann, J. Hoja, R. K. Hylton, L. Iuzzolino, W. Jankiewicz, D. T. de Jong, J. Kendrick, N. J. J. de Klerk, H.-Y. Ko, L. N. Kuleshova, X. Li, S. Lohani, F. J. J. Leusen, A. M. Lund, J. Lv, Y. Ma, N. Marom, A. E. Masunov, P. McCabe, D. P. McMahon, H. Meekes, M. P. Metz, A. J. Misquitta, S. Mohamed, B. Monserrat, R. J. Needs, M. A. Neumann, J. Nyman, S. Obata, H. Oberhofer, A. R. Oganov, A. M. Orendt, G. I. Pagola, C. C. Pantelides, C. J. Pickard, R. Podeszwa, L. S. Price, S. L. Price, A. Pulido, M. G. Read, K. Reuter, E. Schneider, C. Schober, G. P. Shields, P. Singh, I. J. Sugden, K. Szalewicz, C. R. Taylor, A. Tkatchenko, M. E. Tuckerman, F. Vacarro, M. Vasileiadis, A. Vazquez-Mayagoitia, L. Vogt, Y. Wang, R. E. Watson, G. A. de Wijs, J. Yang, Q. Zhu, C. R. Groom, Acta Crystallogr. B 2016, 72, 439-459.

[6] aJ. Vaara, J. Jokisaari, R. E. Wasylishen, D. L. Bryce, Progr. Nucl. Magn. Reson. Sp. 2002, 41, 233 - 304; bA. Lesage, in eMagRes (Eds.: R. K. Harris, R. E. Wasylishen), Wiley-Blackwell, 2008; cR. H. Contreras, J. E. Peralta, C. G. Giribet, M. C. R. de azúa, J. C. Facelli, Vol. 41, Academic Press, 2000, pp. 55 - 184.

[7] aJ. L. Marshall, D. E. Miiller, S. A. Conn, R. Seiwell, A. M. Ihrig, Acc. Chem. Res. 1974, 7, 333-339; bL. B. Krivdin, E. W. Della, Prog. Nucl. Magn. Res. Sp. 1991, 23, 301 - 610.

[8] M. Karplus, J. Am. Chem. Soc. 1963, 85, 2870-2871.

[9] S. Berger, Org. Magn. Reson. 1980, 14, 65-68.

[10] J. H. Lee, F. Li, A. Grishaev, A. Bax, J. Am. Chem. Soc. 2015, 137, 1432--1435.

[11] aP. Sanz Camacho, K. S. Athukorala Arachchige, A. M. Z. Slawin, T. F. G. Green, J. R. Yates, D. M. Dawson, J. D. Woollins, S. E. Ashbrook, J. Am. Chem. Soc. 2015, 137, 6172--6175; bC. Martineau, F. Fayon, C. Legein, J.-Y. Buzaré, G. Silly, D. Massiot, Chem. Commun. 2007, 2720--2722; cD. Massiot, F. Fayon, M. Deschamps, S. Cadars, P. Florian, V. Montouillout, N. Pellerin, J. Hiet, A. Rakhmatullin, C. Bessada, Comptes Rendus Chimie 2010, 13, 117 - 129; dF. Fayon, D. Massiot, M. H. Levitt, J. J. Titman, D. H. Gregory, L. Duma, L. Emsley, S. P. Brown, J. Chem. Phys. 2005, 122, 194313; eS. E. Ashbrook, D. McKay, Chem. Commun. 2016, 52, 7186-7204; fY. T. A. Wong, J. Landmann, M. Finze, D. L. Bryce, J. Am. Chem. Soc. 2017, 139, 8200-8211; gF. A. Perras, W. C. Ewing, T. Dellermann, J. Böhnke, S. Ullrich, T. Schäfer, H. Braunschweig, D. L. Bryce, Chem. Sci. 2015, 6, 3378-3382.

[12] aS. Cadars, A. Lesage, M. Trierweiler, L. Heux, L. Emsley, Phys. Chem. Chem. Phys. 2007, 9 , 92-103; bJ. M. Griffin, J. R. Yates, A. J. Berry, S. Wimperis, S. E. Ashbrook, J. Am. Chem. Soc. 2010, 132, 15651--15660; cS. Cadars, D. H. Brouwer, B. F. Chmelka, Phys. Chem. Chem. Phys. 
2009, 11, 1825-1837; dD. J. Srivastava, J. H. Baltisberger, P. Florian, F. Fayon, R. A.

Shakhovoy, M. e. Deschamps, N. Sadiki, P. J. Grandinetti, Phys. Rev. B 2018, 98, 134202.

[13] L. Duma, W. C. Lai, M. Carravetta, L. Emsley, S. P. Brown, M. H. Levitt, ChemPhysChem 2004, 5, 815-833.

[14] aS. P. Brown, M. Perez-Torralba, D. Sanz, R. M. Claramunt, L. Emsley, Chem. Commun. 2002, 1852-1853; bS. P. Brown, L. Emsley, J. Magn. Reson. 2004, 171, 43-47; cI. Hung, A.-C. Uldry, J. Becker-Baldus, A. L. Webber, A. Wong, M. E. Smith, S. A. Joyce, J. R. Yates, C. J. Pickard, R. Dupree, S. P. Brown, J. Am. Chem. Soc. 2009, 131, 1820-1834.

[15] S. A. Joyce, J. R. Yates, C. J. Pickard, S. P. Brown, J. Am. Chem. Soc. 2008, 130, 12663-12670.

[16] aJ. R. Yates, Magn. Reson. Chem. 2010, 48, S23-S31; bT. F. G. Green, J. R. Yates, J. Chem. Phys. 2014, 140, 234106.

[17] P. Thureau, G. Mollica, F. Ziarelli, S. Viel, J. Magn. Reson. 2013, 231, 90-94.

[18] J. L. Marshall, L. G. Faehl, R. Kattner, P. E. Hansen, Org. Magn. Reson. 1979, 12, 169-173.

[19] J. L. Marshall, L. G. Faehl, R. Kattner, Org. Magn. Reson. 1979, 12, 163-168.

[20] J. L. Marshall, Carbon-carbon and carbon-proton NMR couplings: applications to organic stereochemistry and conformational analysis, Verlag Chemie International, Deerfield Beach, Florida, 1983.

[21] J.-S. Hu, A. Bax, Journal of the American Chemical Society 1997, 119, 6360-6368.

[22] B. Bose, S. Zhao, R. Stenutz, F. Cloran, P. B. Bondo, G. Bondo, B. Hertz, I. Carmichael, A. S. Serianni, Journal of the American Chemical Society 1998, 120, 11158-11173.

[23] A. C. Wang, A. Bax, Journal of the American Chemical Society 1996, 118, 2483-2494.

[24] aM. Hong, J. D. Gross, R. G. Griffin, J. Phys. Chem B 1997, 101, 5869-5874; bX. Feng, Y. K. Lee, D. Sandstrom, M. Edén, H. Maisel, A. Sebald, M. H. Levitt, Chem. Phys. Lett. 1996, 257, 314-320; cR. Suardíaz, R. Crespo-Otero, C. Pérez, J. S. Fabián, J. M. G. d. 1. Vega, J. Chem. Phys. 2011, 134, 061101; dY. Shen, F. Delaglio, G. Cornilescu, A. Bax, J. Biomol. NMR 2009, 44, 213-223; eY. Shen, A. Bax, J. Biomol. NMR 2013, 56, 227-241.

[25] aA. Hofstetter, M. Balodis, F. M. Paruzzo, C. M. Widdifield, G. Stevanato, A. C. Pinon, P. J. Bygrave, G. M. Day, L. Emsley, Journal of the American Chemical Society 2019; bG. Mollica, M. Dekhil, F. Ziarelli, P. Thureau, S. Viel, Angew. Chem. Int. Ed. 2015, 54, 6028-6031. 